\title{
A Study of Ablation-Flowfield Coupling Relevant to the Orion Heatshield
}

\author{
Christopher O. Johnston, ${ }^{*}$ Peter A. Gnoffo ${ }^{\dagger}$ \\ and Alireza Mazaheri ${ }^{\ddagger}$ \\ NASA Langley Research Center, Hampton, VA 23681 USA
}

The coupled interaction between an ablating surface and the surrounding aerothermal environment is studied. An equilibrium ablation model is coupled to the LAURA flowfield solver, which allows the char ablation rate $\left(\dot{m}_{c}\right)$ to be computed as part of the flowfield solution. The wall temperature $\left(T_{w}\right)$ and pyrolysis ablation rate $\left(\dot{m}_{g}\right)$ may be specified by the user, obtained from the steady-state ablation approximation, or computed from a a material response code. A 32 species thermochemical nonequilibrium flowfield model is applied, which permits the treatment of $\mathrm{C}, \mathrm{H}, \mathrm{O}, \mathrm{N}$, and $\mathrm{Si}$ containing species. Coupled ablation cases relevant to the Orion heatshield are studied. These consist of diffusionlimited oxidation cases with Avcoat as the ablation material. The $\dot{m}_{c}$ values predicted from the developed coupled ablation analysis were compared with those obtained from a typical uncoupled ablation analysis. The coupled results were found to be as much as $50 \%$ greater than the uncoupled values. This is shown to be a result of the cumulative effect of the two fundamental approximations inherent in the uncoupled analysis.

\section{Nomenclature}

Blowing reduction constant $=0.5$

Char emissivity

Char density $\left(\mathrm{kg} / \mathrm{m}^{2}\right)$

Density of virgin material $\left(\mathrm{kg} / \mathrm{m}^{2}\right)$

Stefan-Boltzmann constant $=5.66961 \mathrm{e}-8 \mathrm{~W} /\left(\mathrm{m}^{2} \mathrm{~K}^{4}\right)$

Shear stress

Mixing length damping factor

Blowing parameter $=\dot{m} / C_{H, 0}$

Non-dimensional char ablation rate $=\dot{m}_{c} / C_{H}$

Non-dimensional pyrolysis ablation rate $=\dot{m}_{g} / C_{H}$

Mass fraction of element $k$ in the char gas

Mass fraction of element $k$ at the boundary layer edge

Mass fraction of element $k$ in the pyrolysis gas

Mass fraction of element $k$ at the wall

Mass fraction of atomic carbon at the wall

Dimensional heat-transfer coefficient $\left(\mathrm{kg} /\left(\mathrm{m}^{2} \mathrm{~s}\right)\right)$

Flowfield total enthalpy $(\mathrm{J} / \mathrm{kg})$

Enthalpy of gas at wall $(\mathrm{J} / \mathrm{kg})$

Enthalpy of solid char at $T_{w}(\mathrm{~J} / \mathrm{kg})$

Enthalpy of pyrolysis gas in equilibrium at $T_{w}$ and $p_{w}(\mathrm{~J} / \mathrm{kg})$

Diffusion mass flux of element $\mathrm{k}\left(\mathrm{kg} /\left(\mathrm{m}^{2} \mathrm{~s}\right)\right.$

Equilibrium constant for the heterogenous reaction $C$ (solid $) \rightarrow C($ gas $)\left(\mathrm{kg}-\mathrm{mol} / \mathrm{m}^{3}\right)$

Mass flux of surface char $\left(\mathrm{kg} /\left(\mathrm{m}^{2} \mathrm{~s}\right)\right)$

*Aerospace Engineer, Aerothermodynamics Branch, Research Technology Directorate, AIAA member.

$\dagger$ Aerospace Engineer, Aerothermodynamics Branch, Research Technology Directorate, AIAA Fellow.

¥Aerospace Engineer, Aerothermodynamics Branch, Research Technology Directorate, AIAA member. 
$\dot{m}_{g} \quad$ Mass flux of pyrolysis gas at the surface $\left(\mathrm{kg} /\left(\mathrm{m}^{2} \mathrm{~s}\right)\right)$

$\dot{m} \quad$ Total mass flux at the surface $=\dot{m}_{c}+\dot{m}_{g}\left(\mathrm{~kg} /\left(\mathrm{m}^{2} \mathrm{~s}\right)\right)$

$M_{C} \quad$ Molecular weight of carbon $=12.01 \mathrm{~kg} / \mathrm{kg}-\mathrm{mol}$

$q_{c} \quad$ Convective heat flux at surface $\left(\mathrm{W} / \mathrm{cm}^{2}\right)$

$q_{c, 0} \quad$ Non-ablating convective heat flux at surface

$T_{w} \quad$ Wall temperature (K)

$v_{w}^{+} \quad$ Normal velocity at wall divided by friction velocity

\section{Introduction}

The assessment and design of reentry heatshields typically involve an uncoupled ablation-flowfield analysis. This uncoupled analysis consists of applying a non-ablating flowfield prediction, which defines the heat-transfer coefficient, wall enthalpy and wall pressure, to an equilibrium ablation model, which computes the char-ablation rate $\left(\dot{m}_{c}\right)$, pyrolysis ablation-rate $\left(\dot{m}_{g}\right)$, wall-temperature $\left(T_{w}\right)$, and in-depth material properties. The analysis is referred to as "uncoupled" because the influence of $\dot{m}_{c}, \dot{m}_{g}$, and $T_{w}$ on the flowfield prediction are treated approximately within the ablation model, and hence the ablation model is not coupled with the flowfield model. For the diffusion-limited oxidation regime expected for Orion, the fundamental influence of coupling involves the prediction of $\dot{m}_{c}$. The prediction of $\dot{m}_{c}$ is sensitive to the chemical composition at the surface, and vice versa. This coupling requires the detailed treatment of convection and diffusion of chemical species towards and away from the wall. For the uncoupled ablation analysis, two fundamental approximations are required to model this effect, assuming equilibrium ablation. These are defined as follows:

\section{Approximation \#1:}

The influence of $\dot{m}_{c}$ and $\dot{m}_{g}$ on the heat-transfer coefficient is approximated as

$$
C_{H}=C_{H, 0} \frac{2 \lambda B_{0}}{\exp \left(2 \lambda B_{0}\right)-1}
$$

where $C_{H, 0}$ is the non-abating heat-transfer coefficient. Recall that $C_{H}$ is related to $q_{c}$ as

$$
q_{c}=C_{H}\left(H_{T}-h_{w}\right)
$$

This approximation has been assessed by Thompson and Gnoffo ${ }^{1}$ and Martinelli et al. ${ }^{2}$ for perfect gas flows.

2. Approximation \#2:

The elemental diffusion mass flux at the surface is written as $^{3}$

$$
\tilde{J}_{k}=C_{M}\left(\tilde{c}_{w, k}-\tilde{c}_{e, k}\right)
$$

where it is assumed that $C_{M}=C_{H}$. This approximation allows the elemental mass balance at the wall to be solved algebraically for the elemental mass fractions at the wall: ${ }^{3}$

$$
\tilde{c}_{w, k}=\frac{\tilde{c}_{e, k}+B_{c}^{\prime} \tilde{c}_{c, k}+B_{g}^{\prime} \tilde{c}_{g, k}}{1+B_{c}^{\prime}+B_{g}^{\prime}}
$$

A discussion of this approximation is presented by Bianchi et al. ${ }^{4}$ for graphite ablation.

The purpose of this paper is to assess the validity of the uncoupled ablation analysis, through comparisons with a coupled analysis, for conditions relevant to NASA's Orion CEV. The coupled analysis developed in this work is discussed in Section III, and compared with results of previous studies in Section IV. An assessment of Approximations \#1 and \#2 is presented in Section V assuming fixed values for $\dot{m}_{c}, \dot{m}_{g}$, and $T_{w}$, which allows for the influence of the approximations to be clearly interpreted. Section VI compares the $\dot{m}_{c}$ computed with an uncoupled and coupled analysis, with fixed values for $\dot{m}_{g}$ and $T_{w}$. This comparison addresses the fundamental differences between a coupled and uncoupled analysis for the diffusion-limited oxidation regime of interest for Orion. 


\section{Coupled Ablation in LAURA}

This section presents the details of the developed coupled ablation analysis. The basic flowfield paramaters are presented in Part A, while the governing surface equations are presented in Part B. Definitions of the three developed solution approaches are provided in Part C. Details of the solution procedure are also discussed. Finally, Parts D and E discuss the applied diffusion model and turbulence model, respectively.

\section{A. Applied Flowfield Parameters}

For the cases presented in this work, a two-temperature thermochemcial nonequilibrium flowfield model was applied. The following 32 species were treated throughout the flowfield (including the wall): $\mathrm{N}, \mathrm{N}^{+}$, $\mathrm{NO}, \mathrm{NO}^{+}, \mathrm{N}_{2}, \mathrm{~N}_{2}^{+}, \mathrm{O}, \mathrm{O}^{+}, \mathrm{O}_{2}, \mathrm{O}_{2}^{+}, \mathrm{e}^{-}, \mathrm{C}, \mathrm{C}^{+}, \mathrm{CO}, \mathrm{CO}_{2}, \mathrm{C}_{2}, \mathrm{C}_{3}, \mathrm{C}_{4}, \mathrm{C}_{5}, \mathrm{C}_{2} \mathrm{H}, \mathrm{C}_{2} \mathrm{H}_{2}, \mathrm{CN}, \mathrm{H}, \mathrm{H}_{2}$, $\mathrm{HCN}, \mathrm{CH}, \mathrm{Si}, \mathrm{SiO}, \mathrm{SiO}_{2}, \mathrm{SiC}, \mathrm{Si}_{2}, \mathrm{SiN}$. The thermodynamic properties for these species were obtained from Gordon and Mcbride $^{5}$. The transport properties were obtained from Wright et al. ${ }^{6,7}$ where available. The remaining species were treated using the approximate approach of Svehla ${ }^{8}$ modified as suggested by Park. ${ }^{9}$ The chemical reaction rates were compiled mostly from previous Earth, ${ }^{9}$ Mars,${ }^{10}$ Titan, ${ }^{11}$ and Venus ${ }^{12}$ studies, with the exception of the $\mathrm{Si}$ rates, which were taken from the work of Mick et al. ${ }^{13,14}$ If a given rate (with a different value) was available from more than one source, the hierarchy for choosing a rate was as follows: Fujita et al. ${ }^{12}$ Gocken, ${ }^{11}$ Park et al., ${ }^{9}$ and Park. ${ }^{10}$ Fujita et al. performed an up-to-date critical analysis of many of the rates, which is the reason their rate model is given preference over the others.

\section{B. Governing Surface Equations}

The coupled ablation capability in LAURA, assuming specified values for $\dot{m}_{c}, \dot{m}_{g}$, and $T_{w}$, was presented by Gnoffo, et al. ${ }^{15}$. The present work extends this capability by allowing $\dot{m}_{c}$ to be computed as part of the flowfield solution. The additional equation required for $\dot{m}_{c}$ is the equilibrium char constraint:

$$
\rho_{w} \frac{c_{w, C}}{M_{C}}=K_{c, C}
$$

which assumes that the solid carbon char is in chemical equilibrium with the gas at the surface. The solution of Eq. (5) requires the atomic carbon mass fraction at the wall $\left(c_{w, C}\right)$, which is assumed to be in chemical equilibrium at the wall temperature, pressure, and elemental composition. The elemental composition is obtained from the wall elemental mass balance equation:

$$
\dot{m}_{c}\left(\tilde{c}_{c, k}-\tilde{c}_{w, k}\right)+\dot{m}_{g}\left(\tilde{c}_{g, k}-\tilde{c}_{w, k}\right)-\tilde{J}_{k}=0
$$

The wall pressure $\left(p_{w}\right)$ is obtained from the normal momentum equation:

$$
\frac{d p_{w}}{d z}+\rho_{w} v_{w} \frac{d v_{w}}{d z}=0
$$

where the normal velocity $\left(v_{w}\right)$ is obtained from the mass continuity equation:

$$
\rho_{w} v_{w}=\dot{m}_{c}+\dot{m}_{g}
$$

If the pyrolysis ablation rate $\left(\dot{m}_{g}\right)$ and wall temperature $\left(T_{w}\right)$ are specified, then Eqs. $(5)$ - (8) may be combined with a chemical equilibrium solver to obtain $\dot{m}_{c}$.

For the present study, $\dot{m}_{g}$ and $T_{w}$ are either specified or obtained using the steady-state ablation approximation. The steady-state ablation approximation requires the solution of an approximate surface energy equation:

$$
-q_{c}-\alpha q_{r a d}+\epsilon \sigma T_{w}{ }^{4}+\left(\dot{m}_{c}+\dot{m}_{g}\right) h_{w}=0
$$

which assumes that the char surface and virgin material recede at the same linear rate. The steady-state ablation approximation provides the following relationship for $\dot{m}_{g}$ :

$$
\dot{m}_{g}=\left(\frac{\rho_{v}}{\rho_{c}}-1\right) \dot{m}_{c}
$$




\section{Definitions of Applied Approaches}

To make clear the influence of Approximations \#1 and \#2, solutions will be presented that include both approximations, only Approximation \#1, and neither approximation. These three different approaches are defined as follows:

1. Uncoupled: This approach applies both approximations, and is identical to the typical "uncoupled" approach described in the Introduction. It is applied as a post-processing step to a non-ablating solution, obtained assuming a super-catalytic, radiative equilibrium wall. The non-ablating solution provides $q_{c, 0}, h_{w}$, and $p_{w}$. For a given $\dot{m}_{c}, \dot{m}_{g}$, and $T_{w}$, the elemental composition at the wall is obtained from Eq. (4). With this elemental composition, the species mass fractions and enthalpy are obtained using LAURA's equilibrium chemistry module at the given $T_{w}$ and $p_{w}$. This process is repeated while iterating on $\dot{m}_{c}$ (and $T_{w}$ if it is not specified) until Eq. (5) (and Eq. (9) for $T_{w}$ ) are satisfied. Note that this approach is identical to the application of B' tables often applied in material response codes, although the present approach does not actually apply any pre-computed tables.

2. Partially-Coupled: This approach removes Approximation \#1, but contains Approximation \#2. It consists of a flowfield with coupled ablation, meaning that the injection of ablation products is treated in the flowfield solution. Therefore, Approximation \#1 is not applied because the influence of $\dot{m}$ on $C_{H}$ is explicitly treated. However, this approach uses the approximation for $\tilde{J}_{k}$ in Eq. (3), which means that Approximation \#2 is applied. The species mass fractions and enthalpy at the wall are obtained identically to the uncoupled approach, except that Eq. (1) is not applied for $C_{H}$. Instead, $C_{H}$ is computed directly from the $q_{c}$ computed in the flowfield solution. The iteration procedure for $\dot{m}_{c}$ and $T_{w}$ is also identical to the uncoupled approach.

The application of this approach typically begins by first obtaining a non-ablating flowfield solution. From this, the procedure outlined in the previous paragraph to obtain $\dot{m}_{c}, T_{w}$, and $c_{w, i}$ is executed every 5000 flowfield iterations. In between these surface computations, the pseudo-cells at the wall are updated every 50 flowfield iterations to maintain the computed surface properties, which are assumed equal to the average of the pseudo-cell values and the values in the first cell above the wall. This procedure is very robust and converges for a wide range of ablation rates.

3. Fully-Coupled: This approach avoids the use of Approximations \#1 and \#2. It therefore provides the most rigorous possible application of equilibrium ablation. For this approach, $\tilde{J}_{k, w}$ is computed in detail using the concentration gradients and diffusion coefficients at the wall, instead of using Eq. (3) as done in the Partially-Coupled approach. As a result, Eq. (6) may not be solved algebraically for $\tilde{c}_{w, k}$ to obtain an equation similar to Eq. (4). Instead, Eq. (6) is solved using the approach developed by Gnoffo et al., ${ }^{15}$ which couples the chemical equilibrium equations with the species conservation equations at the surface. This approach was extended in the present study by adding Eq. (5) to this set of equations solved at the surface, which allows $\dot{m}_{c}$ to be obtained as part of the surface iteration procedure.

The application of this approach typically begins by first obtaining a Partialy-Coupled solution. It was found that the coupled set of surface equations require an reasonable initial solution for convergence. If the solution of $T_{w}$ is also desired (meaning it is not specified), then the surface energy equation is solved every 1000 flowfield iterations. It was found that the surface energy equation causes serious convergence problems if it is coupled directly to the other surface equations.

\section{Diffusion Modeling}

The "approximate-corrected" diffusion model proposed by Sutton and Gnoffo ${ }^{16}$ is typically applied for aerothermodynamic simulations. This model has been shown to produce $q_{c}$ values that compare very well with the exact model provided by the Stefan-Maxwell equations. ${ }^{17,18}$ The species compositions through the boundary layer predicted by the approximate-corrected approach, however, may be noticeably different than the Stefan-Maxwell result. To illustrate this, Fig. 1 compares the mass fractions of elemental oxygen along the stagnation-line for a $3.6 \mathrm{~m}$ radius sphere in air with free-stream velocity and density values of 8.0 $\mathrm{km} / \mathrm{s}$ and $3 \times 10^{-3} \mathrm{~kg} / \mathrm{m}^{3}$, respectively. Note that nitrogen is the only other element present in this case, and its mass fraction is equal to $1-\tilde{c}_{O}$. The wall is assumed to be equilibrium catalytic. It is seen that the Stefan-Maxwell approach predicts $8 \%$ more elemental oxygen at the surface than the approximate-corrected 
approach. Both approaches predict a stagnation point $q_{c}$ of $99.9 \mathrm{~W} / \mathrm{cm}^{2}$. The deviation of the elemental oxygen mass fractions in the boundary layer from the free-stream (and boundary layer edge) value of 0.24 has been observed by other researchers. ${ }^{19,20}$

With the introduction of ablation, the deviation in the elemental mass fraction predicted by the approximatecorrected and Stefan-Maxwell approaches decreases. This is shown in Fig. 2, which compares all the elements present for an Avcoat ablation case, except nitrogen. The details of the ablator composition and ablation rates for this case will be present later in Fig. 13. The free-stream conditions are identical to those for Fig. 1. The presence of ablation tends to decrease the severe species gradients present in a pure air boundary layer. This is a result of nearly all the elemental oxygen combining with $\mathrm{C}$ to produce $\mathrm{CO}$, which occurs rather gradually throughout the boundary layer. With all the elemental oxygen going to $\mathrm{CO}$, recombination of $\mathrm{O}_{2}$ near the wall (and its associated large $\mathrm{O}_{2}$ gradient) is prevented.

The ultimate goal of the present work is to compute $\dot{m}_{c}$ from Eq. (5) as part of the flowfield solution. Since Eq. (5) is dependent on the atomic carbon mass fraction at the wall, the prediction of $\dot{m}_{c}$ will be very sensitive to the species diffusion near the surface. Although Fig. 2 showed that the approximate-corrected approach agrees well with the Stefan-Maxwell approach, it was found to under-predict $\dot{m}_{c}$ by up to $10 \%$ (this applies to the Fully-Coupled ablation approach). Therefore, it was decided to apply the Stefan-Maxwell approach for the coupled ablation cases presented in this paper.

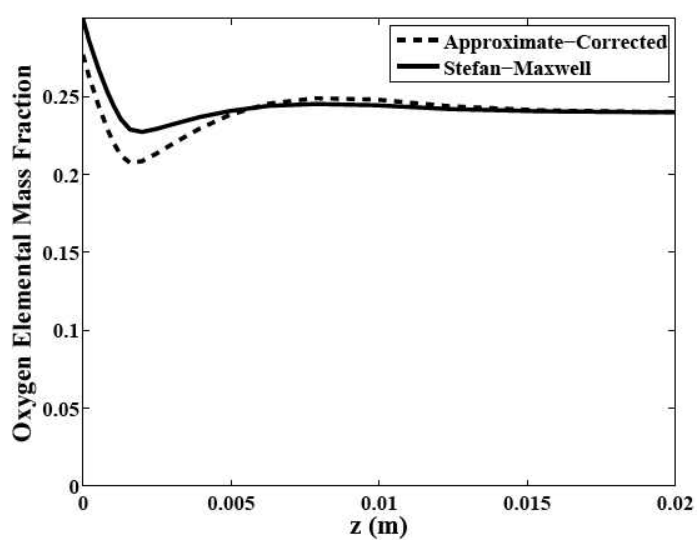

Figure 1: Elemental mass fractions of oxygen through the stagnation line boundary layer

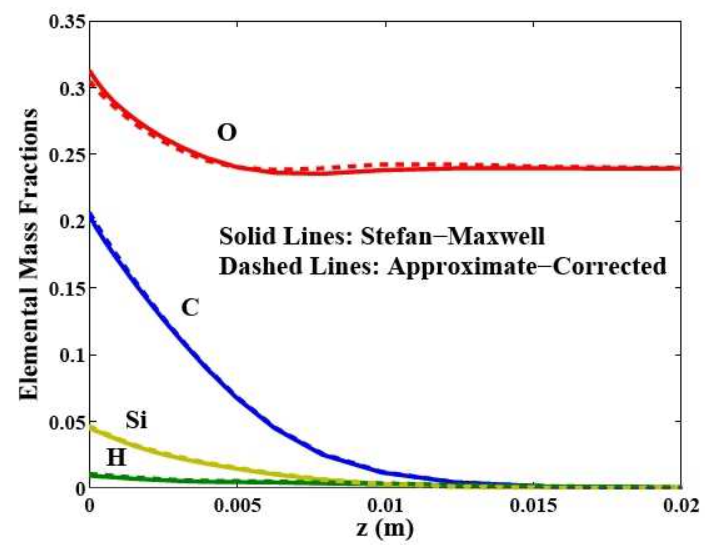

Figure 2: Elemental mass fractions of oxygen through the stagnation line boundary layer

\section{E. Turbulence Modeling}

Turbulence is treated in the present study using the Cebeci-Smith model, modified for a pressure gradient and surface mass transfer. These modifications are implemented through the mixing length damping factor, $A^{+}$, which is written presently as:

$$
A^{+}=26\left(\left|\tau_{w} / \tau\right|\right)^{1 / 2} \exp \left(-5.9 v_{w}^{+}\right)
$$

The term $\left(\left|\tau_{w} / \tau\right|\right)^{1 / 2}$ accounts for a pressure gradient, ${ }^{21}$ and is standard in LAURA's Cebeci-Smith and Baldwin-Lomax models. ${ }^{22}$ The term $\exp (-$ $\left.5.9 v_{w}^{+}\right)$accounts for surface mass transfer, as proposed by $\mathrm{Cebeci}^{23}$ and based on the work of Bushnell and Beckwith. ${ }^{24}$ The turbulent Schmidt $\left(S c_{\text {turb }}\right)$ and Prandtl $\left(P r_{\text {turb }}\right)$ numbers are set equal to 1.0. To show the influence of the two modifications in Eq. (8), both a non-ablating and ablating case were studied with and without these modifica-

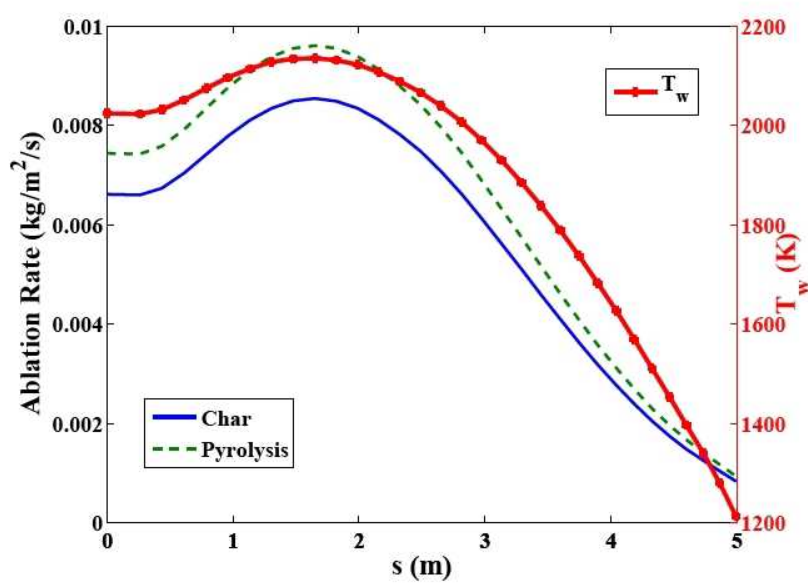

Figure 3: Specified ablation rates and wall temperature. tions. The geometry and free stream conditions are 
the same as those applied in Section III.D. For the ablating case, $\dot{m}_{g}, \dot{m}_{c}$, and $T_{w}$ are specified to the values shown in Fig. 3. The resulting convective heating distributions are shown in Fig. 4 for the ablating case and Fig. 5 for the non-ablating case. The "Baseline" result shown in these figures refers to the application of Eq. (11), which contains both the pressure gradient and mass-transfer modifications. The " $A^{+}=$ 26 " result removes both of these modifications, while the "No mass-transfer corr." result removes only the mass-transfer correction. For the ablating case, Fig. 4 indicates that removing the mass-transfer correction provides a slight decrease in $q_{c}$, while the pressure gradient correction has a negligible influence. For the non-ablaitng case, Fig. 5 shows that removing the pressure gradient correction (represented by the $A^{+}=26$ result because the mass-transfer correction has no influence) provides a slight increase in $q_{c}$.

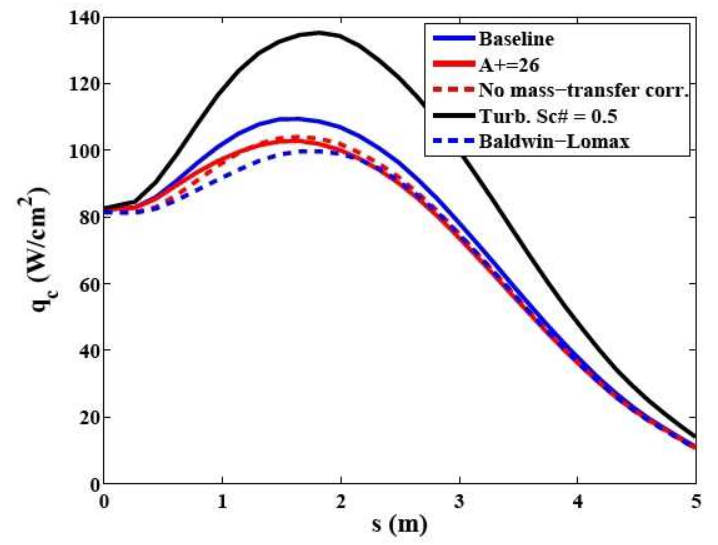

Figure 4: Convective heating along the body for ablation rates and $T_{w}$ specified in Fig. 3.

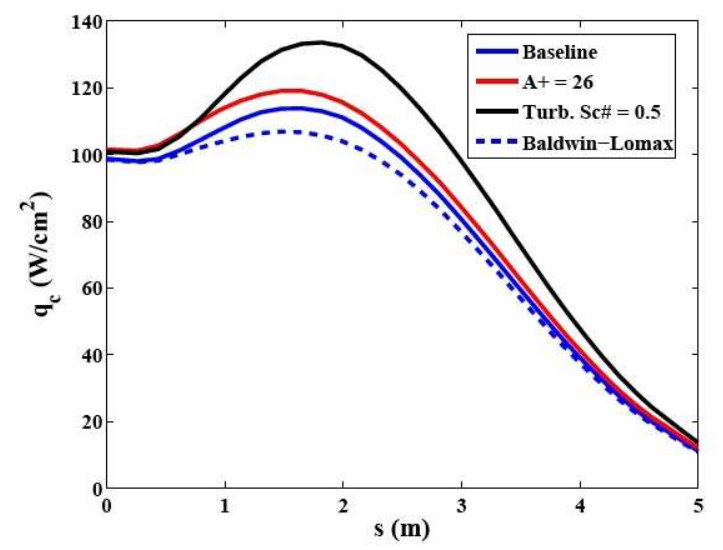

Figure 5: Convective heating along the body for the non-ablating case.

The influence of $S c_{t u r b}$ is shown in Figs. 4 and 5 through the "Turb. Sc\# $=0.5$ " result, which applies Eq. (11) with a $S c_{\text {turb }}=0.5$, instead of the value of 1.0 applied for the other results. It is clear from the figures that lowering the $S c_{\text {turb }}$ significantly increases $q_{c}$ in the turbulent regions. Note that $q_{c}$ at $s=2.0 \mathrm{~m}$ is slightly larger for the ablating case with $S c_{t u r b}=0.5$. This is a result of the increased contribution from the diffusive component of $q_{c}$, which actually increases with the introduction of ablation. This behavior will be discussed in more detail later.

The result of the Baldwin-Lomax turbulence model is also shown in Figs. 4 and 5. This model includes the pressure gradient correction, but not the mass-transfer correction. It is seen to compare relatively well with the "Baseline" model for both the ablating and non-abalting case.

\section{Comparison with Previous Studies}

This section compares the developed coupled ablation capability with the results of three previous studies. ${ }^{25-27}$ These studies were chosen because they consider cases in the diffusion-limited oxidation regime of present interest, and they assume equilibrium ablation. As will be shown, the agreement obtained with these studies is not generally good. The possible reasons for this are discussed.

\section{A. Comparison with Results of Bartlett et al. for Avcoat}

Bartlett et al. ${ }^{25}$ present coupled steady-state ablation results (meaning $T_{w}$ and $\dot{m}_{g}$ are computed from Eqs. (9) and (10)) for the stagnation point of a $3.96 \mathrm{~m}$ radius sphere. These results were obtained using the BLIMP program. ${ }^{28}$ The ablation material considered was Avcoat. Both coking and mechanical silica removal were assumed, which leads to the elemental mass fractions shown in Table 1.

The present Fully-Coupled results are compared with the coupled results of Bartlett et al. in Table 2 for three cases. It is seen that the present prediction for $\dot{m}$ is $\sim 35 \%$ larger than the Bartlett et al. prediction. These larger values are the result of two combined effects: The first is the larger $q_{c}$ (and $q_{c, 0}$ ) value predicted in the present approach. Because these cases are all in the diffusion-limited oxidation

Table 1: Elemental mass fractions assumed for the Bartlett et al. Avcoat study.

\begin{tabular}{lcc}
\hline Element & Char & Pyrolysis \\
\hline C & 1.0 & 0.37 \\
H & 0.0 & 0.13 \\
O & 0.0 & 0.47 \\
N & 0.0 & 0.03 \\
Si & 0.0 & 0.00 \\
\hline
\end{tabular}


regime, it can be written from Eq. (3) that

$$
\dot{m} \approx\left(\frac{q_{c}}{H_{T}-h_{w}}\right) B^{\prime}
$$

where $B^{\prime}$ is a constant for this case equal to $\sim 0.4$. Although this equation is explicitly applied only in the Partially-Coupled approach, it is still approximately true for the Fully-Coupled approach. The second cause for the difference between the present results and those of Bartlett et al. is the influence of treating unequal diffusion at the wall. This effect is indicated by the ratio between the Partially-Coupled and Fully-Coupled $\dot{m}$, which is shown in the last column of the table. The present results are seen to predict a Fully-Coupled $\dot{m}$ slightly larger than the Partially-Coupled value. Conversely, Bartlett et al. predicts the Fully-Coupled $\dot{m}$ to be $15-20 \%$ lower than the Partially-Coupled value.

Table 2: Comparison of Bartlett et al. results (in parenthesis) with the present Fully-Coupled results (not in parenthesis).

\begin{tabular}{cccccccc}
\hline Case & $\begin{array}{c}U_{\text {inf }} \\
(\mathrm{m} / \mathrm{s})\end{array}$ & $\begin{array}{c}\rho_{\text {inf }} \\
\left(\mathrm{kg} / \mathrm{m}^{3}\right)\end{array}$ & $\begin{array}{c}q_{c, 0} \\
\left(\mathrm{~W} / \mathrm{cm}^{2}\right)\end{array}$ & $\begin{array}{c}q_{c} \\
\left(\mathrm{~W} / \mathrm{cm}^{2}\right)\end{array}$ & $\begin{array}{c}\dot{m} \times 10^{3} \\
\left(\mathrm{~kg} /\left(\mathrm{m}^{2} \mathrm{~s}\right)\right)\end{array}$ & $\begin{array}{c}T_{w} \\
(\mathrm{~K})\end{array}$ & ${\frac{\dot{m}_{\text {fully }}}{\dot{m}_{\text {partially }}}}^{*}$ \\
\hline 1 & 8626 & $1.40 \mathrm{e}-4$ & $80.7(66.5)$ & $70.1(58.7)$ & $7.22(5.34)$ & $1929(1990)$ & $1.02(0.85)$ \\
2 & 7469 & $1.87 \mathrm{e}-4$ & $61.5(51.5)$ & $53.7(46.4)$ & $7.42(5.41)$ & $1805(1877)$ & $1.02(0.81)$ \\
3 & 6099 & $2.81 \mathrm{e}-4$ & $41.4(35.4)$ & $35.6(33.1)$ & $7.69(5.55)$ & $1633(1726)$ & $1.07(0.76)$ \\
\hline
\end{tabular}

${ }^{*}$ Bartlett et al. values assumed equal to $C_{M} / C_{H}$

The differences observed in Table 2 are not understood at this time. Possible explanations involve the updated thermodynamic and transport properties applied in the present case, or the inaccuracies introduced by the bifurcation diffusion approach applied by Bartlett. Also, the present model considers thermochemcial nonequilibrium throughout the flowfield, while Bartlett et al. assumed chemical and thermal equilibrium. The nonequilibrium influence was, however, examined by applying LAURA's free-energy minimization capability to Case 1 . The computed $\dot{m}$ and $q_{c}$ were within $3 \%$ of the nonequilibrium values presented in Table 2 . Thus, the disagreement is not likely due to nonequilibrium effects.

\section{B. Comparison with Previous Stardust Results}

Olynick et al. ${ }^{26}$ and Gupta et al. ${ }^{27}$ present coupled ablation-flowfield analyses for the Stardust vehicle. The study by Olynick et al. coupled a nonequilibrium Navier-Stokes flowfield solver to the FIAT material response code. The FIAT code applies Approximation \#2 to compute $\dot{m}_{c}$, while modeling the in-depth material decomposition to compute $\dot{m}_{g}$. The study by Gupta coupled an equilibrium viscous-shock-layer model to a steady-state ablation model. Both of these studies treated the pre-flight best estimate trajectory.

The present results were obtained using the elemental mass fractions for the Stardust ablator, PICA, presented by Gupta ${ }^{27}$ and listed in Table 3. Steady-state ablation is assumed to compute $\dot{m}_{g}$ and $T_{w}$. To allow a meaningful comparison with Olynick et al., ${ }^{26}$ who did not assume steady-state ablation, trajectory points

Table 3: Elemental mass fractions assumed by Gupta for PICA.

\begin{tabular}{lcc}
\hline Element & Char & Pyrolysis \\
\hline $\mathrm{C}$ & 1.0 & 0.60 \\
$\mathrm{H}$ & 0.0 & 0.11 \\
$\mathrm{O}$ & 0.0 & 0.25 \\
$\mathrm{~N}$ & 0.0 & 0.04 \\
$\mathrm{Si}$ & 0.0 & 0.00 \\
\hline
\end{tabular}
were chosen for which Olynick et al.'s $\dot{m}_{g}$ and $\dot{m}_{c}$ approached the steady-state relationship of Eq. (10), therefore indicating near steady-state ablation. The chosen trajectory points are $t=54$ and $76 \mathrm{~s}$. Tables 4 and 5 compare the present stagnation point results with those of Olynick et al. and Gupta. The present results apply the Partially-Coupled approach to be consistent with the other studies. For $t=54 \mathrm{~s}$, Table 4

Table 4: Comparison of Stardust results at the stagnation point for $t=54 \mathrm{~s}$.

\begin{tabular}{cccc}
\hline & Present & Olynick et al. & Gupta \\
\hline$q_{c, 0}$ & 920 & 1100 & 980 \\
$q_{c}$ & 660 & 640 & 610 \\
$\dot{m}$ & $5.30 \mathrm{e}-2$ & $9.00 \mathrm{e}-2$ & $3.95 \mathrm{e}-2$ \\
$T_{w}$ & 3430 & 3400 & 3300 \\
\hline
\end{tabular}

Table 5: Comparison of Stardust results at the stagnation point for $t=76 \mathrm{~s}$.

\begin{tabular}{cccc}
\hline & Present & Olynick et al. & Gupta \\
\hline$q_{c, 0}$ & 206 & 205 & 200 \\
$q_{c}$ & 195 & 202 & 120 \\
$\dot{m}$ & $3.76 \mathrm{e}-2$ & $3.70 \mathrm{e}-2$ & $1.95 \mathrm{e}-2$ \\
$T_{w}$ & 2481 & 2550 & 2100 \\
\hline
\end{tabular}


shows significant disagreement between the three results. This case is in the sublimation regime, as indicated by the large $T_{w}$ values, and is therefore very sensitive to $T_{w}$ and $q_{c}$. The disagreement in $q_{c, 0}$ suggests that the disagreement between the coupled ablation results is caused by differences in flowfield parameters related to $q_{c}$ (such as chemical rates or transport properties). For $t=76 \mathrm{~s}$, Table 5 shows good agreement between the present results and those of Olynick. This case is in the diffusion-limited oxidation regime, which is the regime of interest for the present study.

\section{Analysis with Fixed Ablation Rates}

To evaluate the differences between the Uncoupled, Partially-Coupled, and Fully-Coupled approaches defined in Section III, cases with specified $\dot{m}_{c}, \dot{m}_{g}$, and $T_{w}$ are studied here for each approach. The validity of Approximation \#1 is assessed by comparing the $C_{H}$ values predicted by the Uncoupled and PartiallyCoupled approaches. Recall that $C_{H}$ is computed from Eq. (1) for the Uncoupled approach, which represents Approximation \#1, while it is computed directly from Eq. (2) for the Partially-Coupled approach. If the $C_{H}$ values agree between the Uncoupled and Partially-Coupled approaches, then Eqs. (3) and (4) will predict the same $\tilde{c}_{w, k}$ values at the surface (because $B_{c}^{\prime}$ and $B_{g}^{\prime}$ will be identical and $C_{M}=C_{H}$ ). Thus, if $\dot{m}_{c}$ was to be computed from Eq. (5) instead of held fixed (as will be done in the next section), then the Uncoupled and Partially-Coupled approaches would predict the same $\dot{m}_{c}$. However, if the predicted $C_{H}$ values differ, then the predicted $\dot{m}_{c}$ would be expected to differ accordingly. Generally, a larger $C_{H}$ translates to a larger $\dot{m}_{c}$.

The validity of Approximation \#2 is assessed by comparing the $\tilde{c}_{w, k}$ values predicted by the PartiallyCoupled and Fully-Coupled approaches. Recall that Approximation \#2 is the only difference between these two approaches. For a given temperature and pressure, the $\tilde{c}_{w, k}$ values define the atomic carbon mass fraction at the wall $\left(c_{w, C}\right)$. The $c_{w, C}$ values are of interest because they are present in the char equilibrium constraint of Eq. (5), which will be applied in the next section to compute $\dot{m}_{c}$. Generally, a larger $c_{w, C}$ in the present analysis will translate to a smaller $\dot{m}_{c}$ in the computed- $\dot{m}_{c}$ analysis of the next section. It will be convenient to compare $\tilde{c}_{w, k}$ values, as they provide a compact means for interpreting the chemical composition at the surface. Typically, larger values of $\tilde{c}_{w, C}$ are associated with larger values of $\tilde{c}_{w, O}$, because $\mathrm{CO}$ is the dominant species (along with $\mathrm{N}_{2}$ ) at the surface. The lower the $\tilde{c}_{w, O}$ value, the less $\mathrm{CO}$ that can be formed, and the more $\tilde{c}_{w, C}$ that is available for forming atomic carbon.

To examine the influence of the char and pyrolysis elemental composition on the coupled ablation behavior, the three different compositions listed in Table 6 are considered. The first of these, labeled Avcoat A, represents the heritage Apollo Avcoat defined by Bartlett. ${ }^{25}$ The second of these, labeled Avcoat B, is the same as Avocat A, except with all the $\mathrm{H}$ removed. This case will allow the influence of $\mathrm{H}$ to be assessed. Finally, Avcoat C represents the composition studied in Section IV, which approximates the influence of coking and mechanical silica removal. ${ }^{29}$

Table 6: Elemental mass fractions applied in this study for Avcoat.

\begin{tabular}{c|ll|ll|ll|}
\hline \multirow{2}{*}{ Element } & \multicolumn{2}{|c|}{ Avcoat A } & \multicolumn{2}{c|}{ Avcoat B } & \multicolumn{2}{c}{ Avcoat C } \\
& Char & Pyrolysis & Char & Pyrolysis & Char & Pyrolysis \\
\hline C & 0.49 & 0.55 & 0.49 & 0.60 & 1.0 & 0.37 \\
$\mathrm{H}$ & 0.0 & 0.09 & 0.0 & 0.0 & 0.0 & 0.13 \\
$\mathrm{O}$ & 0.27 & 0.34 & 0.27 & 0.38 & 0.0 & 0.47 \\
$\mathrm{~N}$ & 0.0 & 0.02 & 0.0 & 0.02 & 0.0 & 0.03 \\
$\mathrm{Si}$ & 0.24 & 0.0 & 0.24 & 0.0 & 0.0 & 0.0 \\
\hline
\end{tabular}

The present analysis was applied to a $3.6 \mathrm{~m}$ radius sphere at a free-stream velocity and density of $6.0 \mathrm{~km} / \mathrm{s}$ and $3.0 \mathrm{e}-4 \mathrm{~kg} / \mathrm{m}^{3}$, respectively. The specified ablation rates and wall temperatures along the body are shown in Fig. 6. So that these specified values would have reasonable profiles and magnitudes, they were obtained assuming steady-state ablation and using the Partially-Coupled approach (for Avcoat A). For the laminar case, the resulting stagnation-point surface properties predicted using the Uncoupled, Partially-Coupled, and Full-Coupled approaches are listed in Table 7. Results are presented for the three Avcoat compositions listed in Table 6. As mentioned previously, the influence of Approximation \#1 is seen by comparing the $C_{H}$ values predicted by the Uncoupled and Partially-Coupled approaches. 
For each of the Avcoat compositions, Table 7 shows that the Uncoupled $C_{H}$ is $7-15 \%$ larger than the PartiallyCoupled value. This indicates that the Uncoupled approach will likely predict, for the computed $-\dot{m}_{c}$ analysis presented in the next section, a larger $\dot{m}_{c}$ than the Partially-Coupled approach. Also mentioned previously, the influence of Approximation \#2 is seen by comparing the $\tilde{c}_{w, k}$ values predicted by the Partially-Coupled and Fully-Coupled approaches. For each of the Avcoat compositions, Table 7 shows that the Parially-Coupled $\tilde{c}_{w, C}$ value is $10 \%$ smaller than the Fully-Coupled value, while the $\tilde{c}_{w, O}$ value is roughly $20 \%$ smaller. The larger amount of oxygen relative to carbon for the Fully-Coupled approach results in less atomic carbon at the wall, as seen in the last column of Table 7 . For the computed $-\dot{m}_{c}$ analysis, this indicates that the Fully-Coupled approach will

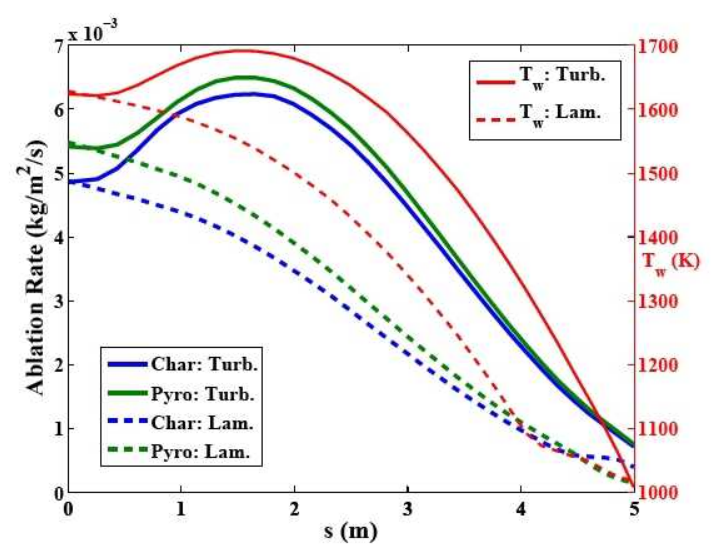

Figure 6: Specified ablation rates and wall temperature. likely predict a larger $\dot{m}_{c}$ than the Partially-Coupled approach. Note that this analysis suggests that Approximations \#1 and \#2 will have offsetting influences in the computed $-\dot{m}_{c}$ analysis when comparing the Uncoupled and Fully-Coupled $\dot{m}_{c}$ values.

Table 7: Comparison of Uncoupled, Partially-Coupled, and Fully-Coupled approaches with fixed $\dot{m}$ and $T_{w}$ at the stagnation-point.

\begin{tabular}{cccccccc}
\hline $\begin{array}{c}\text { Avcoat } \\
\text { Model }\end{array}$ & Approach & $\begin{array}{c}q_{c} \\
\left(\mathrm{~W} / \mathrm{cm}^{2}\right)\end{array}$ & $\begin{array}{c}C_{H} \times 10^{2} \\
\left(\mathrm{~kg} /\left(\mathrm{m}^{2} \mathrm{~s}\right)\right)\end{array}$ & $\tilde{c}_{w, C}$ & $\tilde{c}_{w, O}$ & $\tilde{c}_{w, H}$ & $c_{w, C}$ \\
\hline A & Uncoupled & 38.0 & 2.11 & 0.171 & 0.263 & $1.62 \mathrm{e}-2$ & $4.1 \mathrm{e}-17$ \\
$\mathrm{~A}$ & Partially-Coupled & 34.6 & 1.92 & 0.181 & 0.264 & $1.71 \mathrm{e}-2$ & $3.2 \mathrm{e}-16$ \\
$\mathrm{~A}$ & Fully-Couped & 36.4 & 1.94 & 0.205 & 0.322 & $1.02 \mathrm{e}-2$ & $8.2 \mathrm{e}-19$ \\
\hline B & Uncoupled & 38.4 & 2.11 & 0.180 & 0.269 & 0.0 & $5.4 \mathrm{e}-14$ \\
B & Partially-Coupled & 33.4 & 1.84 & 0.197 & 0.272 & 0.0 & $1.1 \mathrm{e}-11$ \\
B & Fully-Couped & 34.7 & 1.83 & 0.207 & 0.327 & 0.0 & $6.9 \mathrm{e}-19$ \\
\hline C & Uncoupled & 36.5 & 2.11 & 0.219 & 0.243 & $2.26 \mathrm{e}-2$ & $9.1 \mathrm{e}-13$ \\
C & Partially-Coupled & 34.0 & 1.97 & 0.229 & 0.243 & $2.35 \mathrm{e}-2$ & $5.7 \mathrm{e}-13$ \\
C & Fully-Couped & 35.1 & 2.01 & 0.277 & 0.285 & $1.83 \mathrm{e}-2$ & $8.2 \mathrm{e}-13$ \\
\hline
\end{tabular}

The trends mentioned in the previous paragraph for the stagnation-point, are shown to be true downstream of the stagnation point $(s=2 \mathrm{~m})$ in Table 8 for laminar flow. Although only the results for Avcoat A are shown, the trends are similar for the other cases, as they were in Table 7 . The results for turbulent flow are listed in Table 9. The Uncoupled and Partially-Coupled $C_{H}$ values along the body are compared in Fig. 7 for the turbulent and laminar cases. The $C_{H}$ differences between the Uncoupled and Partially-Coupled approaches seen here for the turbulent case are not consistent with the downstream laminar results. Instead of the Uncoupled $C_{H}$ being $7-15 \%$ larger than the Partially-Coupled value, it is seen to be roughly $15 \%$ smaller than the Partially-Coupled value. This difference will have a significant influence on the computed $\dot{m}_{c}$ analysis presented in the next section. This is especially true because the trends in the $\tilde{c}_{w, k}$ values predicted by the Partially-Coupled and Fully-Coupled approaches, and compared along the body in Fig 8, are similar to the laminar case. This means that Approximations \#1 and \#2 will both result in $\dot{m}_{c}$ increases (in contrast to their offsetting increase and decrease for the laminar case).

Table 8: Comparison of Uncoupled, Partially-Coupled, and Fully-Coupled approaches with fixed $\dot{m}$ and $T_{w}$ for the laminar case at $s=2 \mathrm{~m}$.

\begin{tabular}{cccccccc}
\hline $\begin{array}{c}\text { Avcoat } \\
\text { Model }\end{array}$ & Approach & $\begin{array}{c}q_{c} \\
\left(\mathrm{~W} / \mathrm{cm}^{2}\right)\end{array}$ & $\begin{array}{c}C_{H} \times 10^{2} \\
\left(\mathrm{~kg} /\left(\mathrm{m}^{2} \mathrm{~s}\right)\right)\end{array}$ & $\tilde{c}_{w, C}$ & $\tilde{c}_{w, O}$ & $\tilde{c}_{w, H}$ & $c_{w, C}$ \\
\hline A & Uncoupled & 28.4 & 1.56 & 0.167 & 0.262 & $1.58 \mathrm{e}-2$ & $1.1 \mathrm{e}-20$ \\
$\mathrm{~A}$ & Partially-Coupled & 24.9 & 1.38 & 0.181 & 0.264 & $1.71 \mathrm{e}-2$ & $8.4 \mathrm{e}-18$ \\
$\mathrm{~A}$ & Fully-Couped & 26.6 & 1.40 & 0.199 & 0.322 & $9.74 \mathrm{e}-3$ & $1.5 \mathrm{e}-26$ \\
\hline
\end{tabular}


Table 9: Comparison of Uncoupled, Partially-Coupled, and Fully-Coupled approaches with fixed $\dot{m}$ and $T_{w}$ for the turbulent case at $s=2 \mathrm{~m}$.

\begin{tabular}{cccccccc}
\hline $\begin{array}{c}\text { Avcoat } \\
\text { Model }\end{array}$ & Approach & $\begin{array}{c}q_{c} \\
\left(\mathrm{~W} / \mathrm{cm}^{2}\right)\end{array}$ & $\begin{array}{c}C_{H \times 10^{2}} \\
\left(\mathrm{~kg} /\left(\mathrm{m}^{2} \mathrm{~s}\right)\right)\end{array}$ & $\tilde{c}_{w, C}$ & $\tilde{c}_{w, O}$ & $\tilde{c}_{w, H}$ & $c_{w, C}$ \\
\hline A & Uncoupled & 35.9 & 2.01 & 0.198 & 0.266 & $1.81 \mathrm{e}-2$ & $2.3 \mathrm{e}-13$ \\
A & Partially-Coupled & 41.5 & 2.32 & 0.180 & 0.264 & $1.64 \mathrm{e}-2$ & $3.5 \mathrm{e}-14$ \\
A & Fully-Couped & 42.3 & 2.29 & 0.198 & 0.309 & $1.11 \mathrm{e}-2$ & $4.6 \mathrm{e}-24$ \\
\hline
\end{tabular}

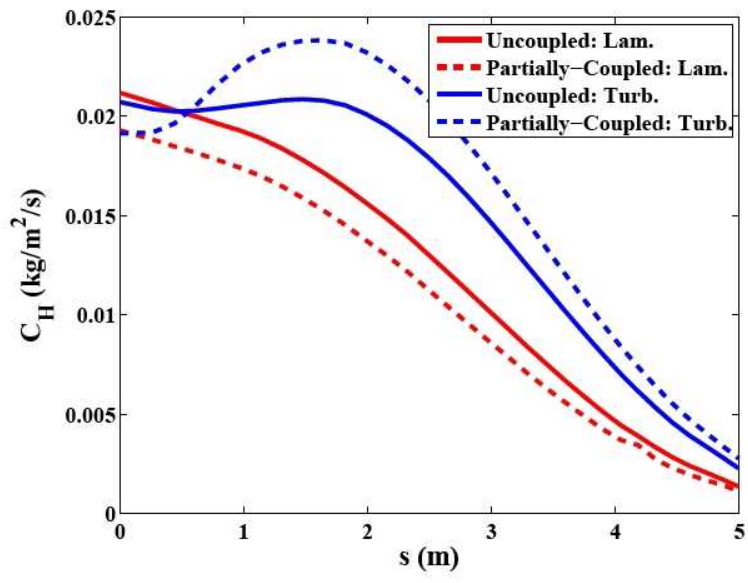

Figure 7: Predicted $C_{H}$ values along the body.

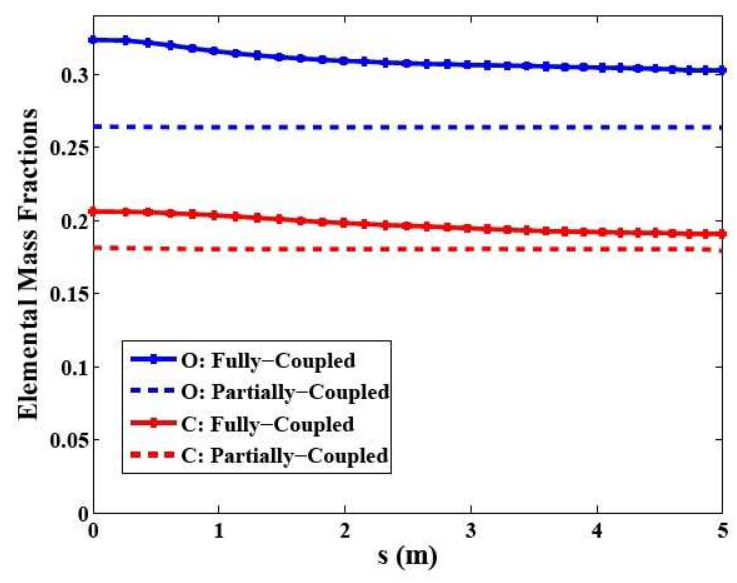

Figure 8: Predicted $\tilde{c}_{w, k}$ values along the body for the turbulent case.

The inaccuracy of Approximation \#1 in turbulent regions was observed in the previous paragraph. This behavior is anticipated to have a significant influence on the computed $\dot{m}_{c}$ analysis presented in the next section. Therefore, it will be studied in more detail here. The non-ablating $\left(q_{c, 0}\right)$, Uncoupled, and PartiallyCoupled $q_{c}$ values are compared in Fig. 9 for the turbulent Avcoat A case. This figure shows that the Partially-Coupled $q_{c}$ becomes nearly equal to the non-ablating value in the downstream turbulent regions. This behavior is not followed by the Uncoupled approach, which is the reason for the disagreement in the $C_{H}$ values shown in Fig. 7 . Note that $q_{c}$ may be separated into two components, the conductive component:

$$
q_{c, \text { cond }}=k_{v e} \frac{d T_{v e}}{d z}+k_{t r} \frac{d T_{t r}}{d z}
$$

and the diffusive component:

$$
q_{c, \text { diff }}=\rho \sum_{i=\text { species }} J_{i} h_{i}
$$

These components are presented in Fig. 10 for the non-ablating and Partially-Coupled cases. It is seen that the conductive component is reduced and the diffusive component is increased with the introduction of ablation. The increase of the diffusive component at the stagnation point (therefore, not influenced by turbulence) is a result of the different chemistry near the wall for the ablating case. The larger increase of the diffusive component downstream of the stagnation point, however, is a result of turbulence. This turbulent downstream region was shown in Fig. 4 to depend strongly on the $S c_{t u r b}$, and less so on the other details of the turbulence model. If $S c_{\text {turb }}$ is increased above the present value of 1.0, the influence of turbulent diffusion decreases. If a large $S c_{\text {turb }}$ value is applied to both the non-ablating (which drives the Uncoupled result) and Partially-Coupled solutions, the agreement between the Uncoupled and Partially-Coupled $q_{c}$ (and $C_{H}$ ) values becomes significantly better. 


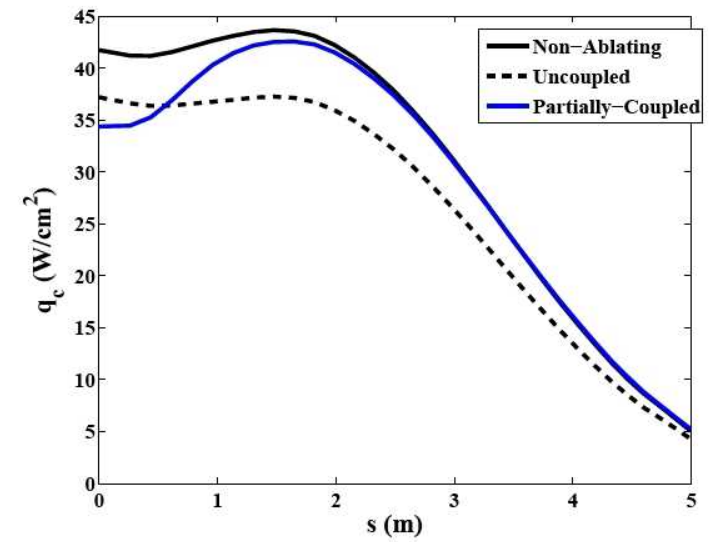

Figure 9: Comparison of $q_{c}$ values along the body for the turbulent case.

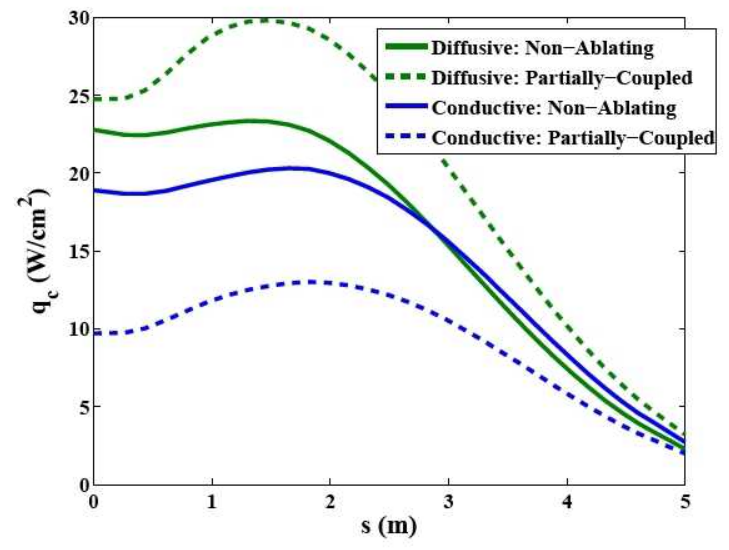

Figure 10: Comparison of the diffusive and conductive components for the turbulent case.

\section{Analysis with Computed Char Ablation Rates}

The present section engages Eq. (5) to allow $\dot{m}_{c}$ to be computed as part of the flowfield solution. The differences in the $\dot{m}_{c}$ predicted using the Uncoupled, Partially-Coupled, and Fully-Coupled approaches are of particular interest, and are the main results of this paper. The $\dot{m}_{g}$ and $T_{w}$ values are fixed to the same values as in the previous section. Note that the restriction of fixed $T_{w}$ could be easily removed by applying Eq. (9). This was not done here to simplify the interpretation of the results, and because in the diffusion-limited regime studied here, $T_{w}$ has a weak influence on $\dot{m}_{c}$. It is assumed that for practical applications a material response code will provide $\dot{m}_{g}$, and this value will likely not be sensitive to $\dot{m}_{c}$. Thus, holding $\dot{m}_{g}$ fixed in the present study is justified.

The differences in $q_{c}, C_{H}$, and $\tilde{c}_{w, k}$ predicted by the Uncoupled, Partially-Coupled, and Fully-Coupled approaches were presented in the previous section for fixed $\dot{m}_{c}$ values (with $\dot{m}_{g}$ and $T_{w}$ also fixed). In the discussion of those results, the results of the present section were correctly anticipated, as will be shown.

\section{A. Case 1}

The first case to be studied is the same as that considered in Section $\mathrm{V}$, that being a $3.6 \mathrm{~m}$ radius sphere at a free-stream velocity and density of $6.0 \mathrm{~km} / \mathrm{s}$ and $3.0 \mathrm{e}-4 \mathrm{~kg} / \mathrm{m}^{3}$. The $\dot{m}_{g}$ and $T_{w}$ values are fixed to those shown in Fig. 6. The resulting $\dot{m}_{c}$ and $q_{c}$ values are listed in Table 10 for the laminar case at $s=$ $0.0 \mathrm{~m}$ and $2.0 \mathrm{~m}$, and the turbulent case for $s=2.0 \mathrm{~m}$. The $\dot{m}_{c}$ values computed for Avcoat B are presented along the body in Figs. 11 and 12 for the laminar and turbulent cases, respectively. For the laminar case, the Fully-Coupled $\dot{m}_{c}$ is only slightly larger than the Uncoupled result, while it is $10-20 \%$ larger than the Partially-Coupled result. This peculiar result that the Uncoupled approach is in better agreement (with the Fully-Coupled approach) than the Partially-Coupled approach was to be expected from Section V, which showed that for the laminar case Approximations \#1 and \#2 result in offsetting errors. In other words, removing Approximation \#1 causes the $\dot{m}_{c}$ difference seen between the Uncoupled and Partially-Coupled approaches, which for the laminar case is a $20 \%$ decrease in $\dot{m}_{c}$. This is a result of Approximation \#1 over-predicting $C_{H}$, as was shown in Fig. 7. Similarly, removing Approximation \#2 causes the $\dot{m}_{c}$ difference seen between the Partially-Coupled and Fully-Coupled approaches, which for the laminar case is about a $23 \%$ increase in $\dot{m}_{c}$.

For the turbulent results listed in Table 10 and shown in Fig. 12, the comparison between approaches in the downstream region is significantly different than the laminar results. As was discussed in Section V, in regions of turbulence Approximation \#1 under-predicts $C_{H}$, which is the opposite of the laminar trend. As a result, removing Approximation \#1 causes an increase in $\dot{m}_{c}$. The influence of Approximation \#2 is the same for the turbulent case as it is for the laminar case, and therefore removing it also causes an increase in $\dot{m}_{c}$. Because removing Approximations \#1 and \#2 both provide increases in $\dot{m}_{c}$, instead of providing offsetting differences as in the laminar case, the difference between the Uncoupled and Fully-Coupled results is significant. For the Avcoat B case, the Fully-Coupled $\dot{m}_{c}$ is $49 \%$ larger than the Uncoupled value at 
$s=2.0 \mathrm{~m}$.

To examine the influence of the fixed $\dot{m}_{g}$ magnitude on the computed $\dot{m}_{c}$, the $\dot{m}_{g}$ values applied in Table 10 were multiplied by 0.33 . The resulting $\dot{m}_{c}$ and $q_{c}$ values are listed in Table 11 for the laminar and turbulent cases. The trends in the three approaches are similar to those observed previously in Table 10. It is therefore concluded that these fundamental trends are not sensitive to $\dot{m}_{g}$ (although the percent differences are).

Table 10: Comparison of Uncoupled, Partially-Coupled, and Fully-Coupled approaches with fixed $\dot{m}$ and $T_{w}$ for the stagnation-point of Case 1.

\begin{tabular}{|c|c|c|c|c|c|c|c|}
\hline $\begin{array}{l}\text { Avcoat } \\
\text { Model }\end{array}$ & Approach & $\begin{array}{c}s=0.0 \\
\dot{m}_{c} \times 10^{3} \\
\left(\mathrm{~kg} /\left(\mathrm{m}^{2} \mathrm{~s}\right)\right)\end{array}$ & $\begin{array}{l}\text { Laminar }^{*} \\
q_{c} \\
\left(\mathrm{~W} / \mathrm{cm}^{2}\right)\end{array}$ & $\begin{array}{c}s=2.0 \mathrm{~m} \\
\dot{m}_{c} \times 10^{3} \\
\left(\mathrm{~kg} /\left(\mathrm{m}^{2} \mathrm{~s}\right)\right)\end{array}$ & $\begin{array}{l}\text { Laminar }^{+} \\
\quad q_{c} \\
\left(\mathrm{~W} / \mathrm{cm}^{2}\right)\end{array}$ & $\begin{array}{c}s=2.0 \mathrm{~m} \\
\dot{m}_{\mathrm{c}} \times 10^{3} \\
\left(\mathrm{~kg} /\left(\mathrm{m}^{2} \mathrm{~s}\right)\right)\end{array}$ & $\begin{array}{c}\text { Turbulent } \\
\quad q_{c} \\
\left(\mathrm{~W} / \mathrm{cm}^{2}\right)\end{array}$ \\
\hline A & Uncoupled & 5.61 & 37.5 & 4.21 & 27.9 & 4.87 & 36.9 \\
\hline A & Partially-Coupled & 4.87 & 34.6 & 3.48 & 24.9 & 6.08 & 41.5 \\
\hline A & Fully-Couped & 5.53 & 35.0 & 4.24 & 25.3 & 6.90 & 41.8 \\
\hline B & Uncoupled & 5.33 & 38.5 & 4.01 & 28.5 & 4.54 & 38.0 \\
\hline B & Partially-Coupled & 4.27 & 34.3 & 3.25 & 25.5 & 5.21 & 40.5 \\
\hline B & Fully-Couped & 5.64 & 33.4 & 4.32 & 24.7 & 6.76 & 40.2 \\
\hline $\mathrm{C}$ & Uncoupled & 3.81 & 38.5 & 2.80 & 28.6 & 3.70 & 37.3 \\
\hline C & Partially-Coupled & 3.46 & 35.0 & 2.46 & 25.2 & 4.12 & 41.4 \\
\hline C & Fully-Couped & 3.68 & 36.3 & 2.76 & 26.2 & 4.40 & 42.4 \\
\hline
\end{tabular}

\footnotetext{
${ }^{*} \dot{m}_{g}=5.48 \mathrm{e}-3 \mathrm{~kg} /\left(\mathrm{m}^{2} \mathrm{~s}\right)$

$+\dot{m}_{g}=3.91 \mathrm{e}-3 \mathrm{~kg} /\left(\mathrm{m}^{2} \mathrm{~s}\right)$

${ }^{\mathrm{x}} \dot{m}_{g}=6.33 \mathrm{e}-3 \mathrm{~kg} /\left(\mathrm{m}^{2} \mathrm{~s}\right)$
}

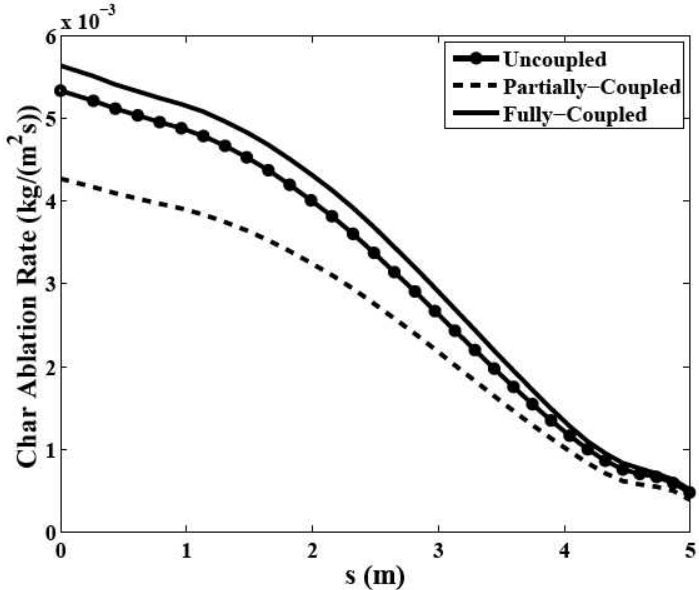

Figure 11: Predicted laminar $\dot{m}_{c}$ values for Case 1 with Avcoat B

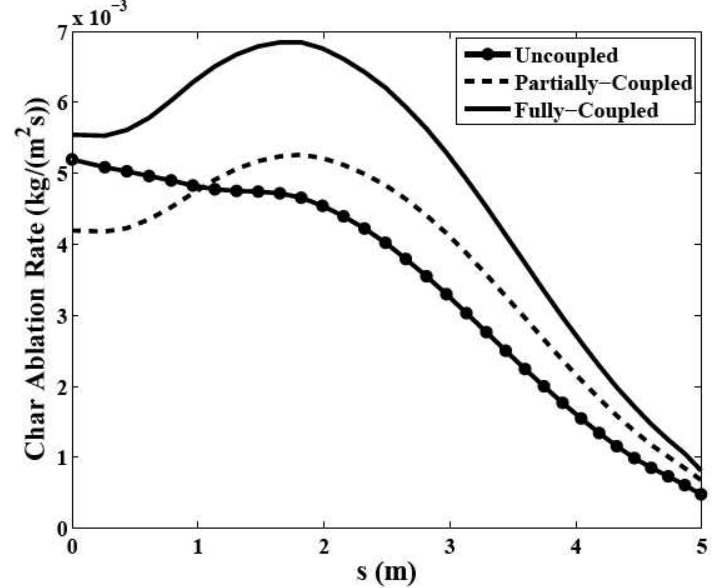

Figure 12: Predicted turbulent $\dot{m}_{c}$ values for Case 1 with Avcoat B

Table 11: Comparison of Uncoupled, Partially-Coupled, and Fully-Coupled approaches for $\dot{m}_{g}$ values equal to $33 \%$ of those applied in Table 10.

\begin{tabular}{|c|c|c|c|c|c|c|c|}
\hline $\begin{array}{l}\text { Avcoat } \\
\text { Model }\end{array}$ & Approach & $\begin{array}{c}s=0.0 \\
\dot{m}_{c} \times 10^{3} \\
\left(\mathrm{~kg} /\left(\mathrm{m}^{2} \mathrm{~s}\right)\right)\end{array}$ & $\begin{array}{l}\text { Laminar }^{*} \\
q_{c} \\
\left(\mathrm{~W} / \mathrm{cm}^{2}\right)\end{array}$ & $\begin{array}{c}s=2.0 \mathrm{~m} \\
\dot{m}_{c} \times 10^{3} \\
\left(\mathrm{~kg} /\left(\mathrm{m}^{2} \mathrm{~s}\right)\right)\end{array}$ & $\begin{array}{c}\text { Laminar }^{+} \\
q_{c} \\
\left(\mathrm{~W} / \mathrm{cm}^{2}\right)\end{array}$ & $\begin{array}{c}s=2.0 \mathrm{~m} \\
\dot{m}_{c} \times 10^{3} \\
\left(\mathrm{~kg} /\left(\mathrm{m}^{2} \mathrm{~s}\right)\right)\end{array}$ & $\begin{array}{c}\text { Turbulent }^{\mathrm{x}} \\
q_{c} \\
\left(\mathrm{~W} / \mathrm{cm}^{2}\right)\end{array}$ \\
\hline A & Uncoupled & 8.52 & 38.4 & 6.29 & 28.5 & 8.22 & 37.9 \\
\hline A & Partially-Coupled & 7.81 & 35.6 & 5.68 & 26.1 & 9.22 & 41.7 \\
\hline A & Fully-Couped & 8.85 & 34.8 & 6.62 & 25.5 & 10.4 & 41.1 \\
\hline
\end{tabular}

${ }^{*} \dot{m}_{g}=1.83 \mathrm{e}-3 \mathrm{~kg} /\left(\mathrm{m}^{2} \mathrm{~s}\right)$

$+\dot{m}_{g}=1.30 \mathrm{e}-3 \mathrm{~kg} /\left(\mathrm{m}^{2} \mathrm{~s}\right)$

${ }^{x} \dot{m}_{g}=2.11 \mathrm{e}-3 \mathrm{~kg} /\left(\mathrm{m}^{2} \mathrm{~s}\right)$ 


\section{B. Case 2}

The second case studied is the same as that considered in Section III.D, that being a $3.6 \mathrm{~m}$ radius sphere at a free-stream velocity and density of $8.0 \mathrm{~km} / \mathrm{s}$ and $3.0 \mathrm{e}-$ $4 \mathrm{~kg} / \mathrm{m}^{3}$. Thus, it is the same as Case 1 , except with a higher velocity. The specified $T_{w}$ and $\dot{m}_{g}$ are shown in Fig. 13 , and the resulting $\dot{m}_{c}$ and $q_{c}$ values are listed in Table 12. The main difference between these results and those of Case 1 is that the Partially-Coupled and FullyCoupled results are in closer agreement for Avcoat A and C. This is also seen in Figure 14, which shows the $\dot{m}_{c}$ distribution along the body for the turbulent Avcoat A case. The Avocat B result presented in Figure 15 shows a significant difference between the Partially-Coupled and Fully-Coupled approaches, similar to that observed for Case 1. The difference between Avcoat A and B is that Avcoat B contains no hydrogen. It is apparent from the

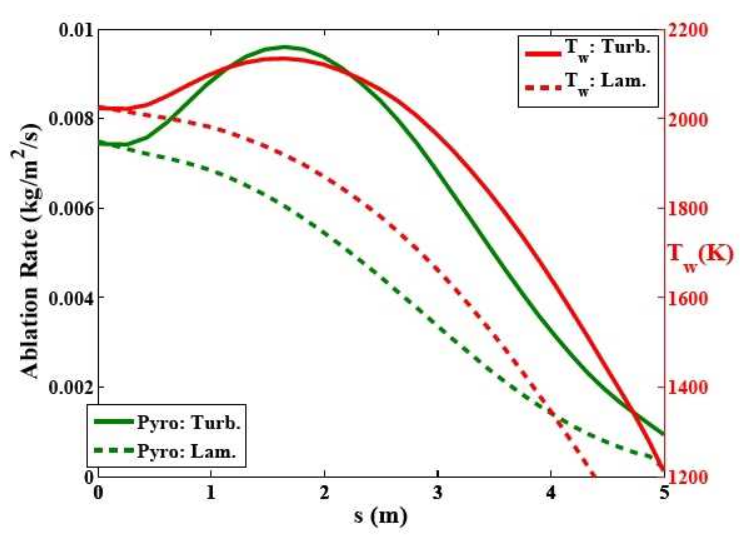

Figure 13: Specified $\dot{m}_{g}$ and $T_{w}$ for Case 2 . present case that the presence of hydrogen reduces the disagreement caused by Approximation \#2. This is not surprising considering the significantly different diffusion characteristics of hydrogen relative to the other heavier species.

Table 12: Comparison of Uncoupled, Partially-Coupled, and Fully-Coupled approaches with fixed $\dot{m}$ and $T_{w}$ for the stagnation-point of Case 2.

\begin{tabular}{|c|c|c|c|c|c|c|c|}
\hline $\begin{array}{r}\text { Avcoat } \\
\text { Model }\end{array}$ & Approach & $\begin{array}{c}s=0.0 \\
\dot{m}_{c} \times 10^{3} \\
\left(\mathrm{~kg} /\left(\mathrm{m}^{2} \mathrm{~s}\right)\right)\end{array}$ & $\begin{array}{c}\text { Laminar }^{*} \\
q_{c} \\
\left(\mathrm{~W} / \mathrm{cm}^{2}\right)\end{array}$ & $\begin{array}{c}s=2.0 \mathrm{~m} \\
\dot{m}_{c} \times 10^{3} \\
\left(\mathrm{~kg} /\left(\mathrm{m}^{2} \mathrm{~s}\right)\right)\end{array}$ & $\begin{array}{c}\text { Laminar }^{+} \\
q_{c} \\
\left(\mathrm{~W} / \mathrm{cm}^{2}\right)\end{array}$ & $\begin{array}{c}s=2.0 \mathrm{~m} \\
\dot{m}_{c} \times 10^{3} \\
\left(\mathrm{~kg} /\left(\mathrm{m}^{2} \mathrm{~s}\right)\right)\end{array}$ & $\begin{array}{c}\text { Turbulent }^{\mathrm{x}} \\
q_{c} \\
\left(\mathrm{~W} / \mathrm{cm}^{2}\right)\end{array}$ \\
\hline A & Uncoupled & 6.90 & 84.0 & 5.24 & 63.3 & 6.94 & 92.7 \\
\hline A & Partially-Coupled & 6.66 & 82.3 & 4.85 & 60.6 & 8.99 & 106.8 \\
\hline A & Fully-Couped & 6.81 & 82.7 & 5.25 & 60.9 & 9.02 & 106.2 \\
\hline B & Uncoupled & 6.49 & 85.9 & 4.95 & 64.4 & 6.40 & 95.3 \\
\hline B & Partially-Coupled & 5.33 & 77.9 & 4.10 & 58.4 & 7.21 & 100.5 \\
\hline B & Fully-Couped & 6.69 & 75.9 & 5.18 & 56.9 & 9.19 & 99.2 \\
\hline C & Uncoupled & 4.87 & 86.0 & 3.64 & 64.9 & 5.36 & 94.0 \\
\hline C & Partially-Coupled & 4.79 & 84.6 & 3.45 & 61.6 & 6.21 & 108.6 \\
\hline C & Fully-Couped & 4.68 & 86.7 & 3.53 & 63.8 & 5.95 & 108.9 \\
\hline
\end{tabular}
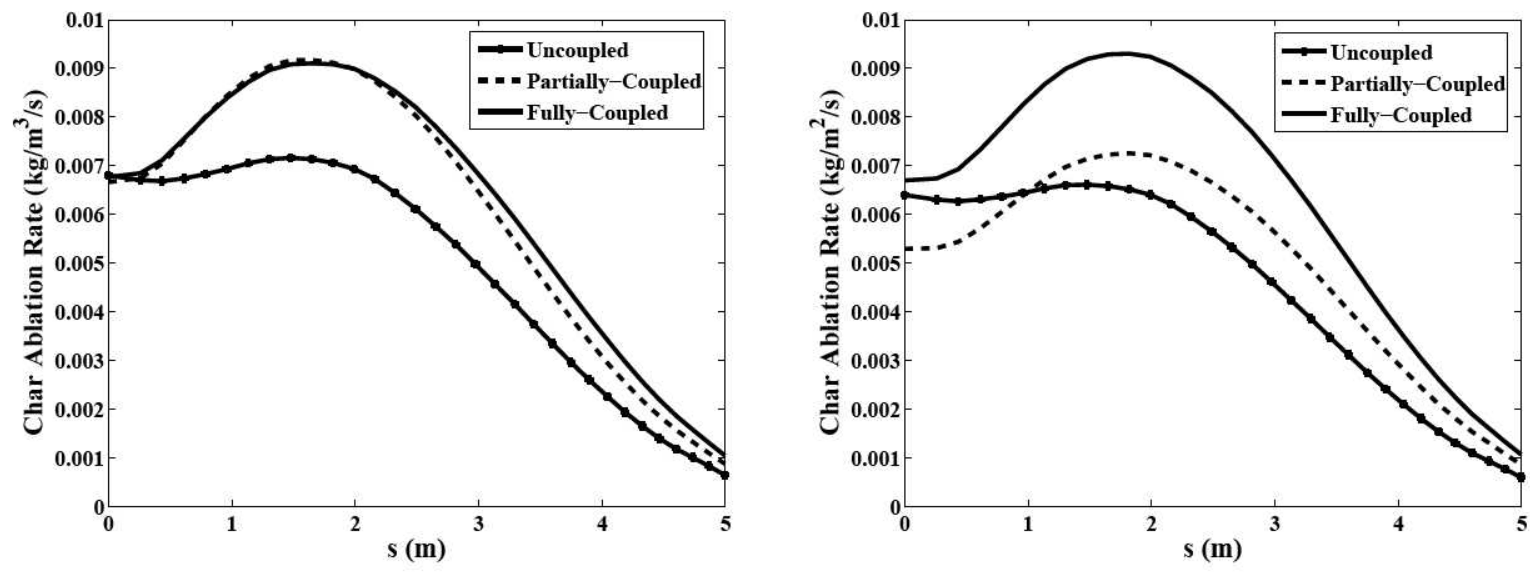

Figure 14: Predicted turbulent $\dot{m}_{c}$ values for Case 2 with Avcoat A. Figure 15: Predicted turbulent $\dot{m}_{c}$ values for Case 2 with Avcoat B. 


\section{Concluding Remarks}

A coupled ablation capability was developed for the LAURA Navier-Stokes flowfield code. This capability includes the ability to treat a thermochemical nonequilibrium flowfield with turbulence and Stefan-Maxwell multicomponent diffusion. A chemical rate model for treating 32 species, including Si species, was compiled. The ability to compute $\dot{m}_{c}$ as part of the flowfield solution was developed for three different approaches. The Uncoupled approach, consistent with typically applied design approaches, is simply a post processing step to a non-ablating flowfield solution. This approach contains Approximation \#1, which represents the blowing correction approximation defined in Eq. 1, and Approximation \#2, which represents the diffusion approximation defined in Eq. 3. The Partially-Coupled approach treats a flowfield with coupled ablation, which removes Approximation \#1, although it applies Approximation \#2. The Fully-Coupled approach treats a flowfield with coupled ablation and does not apply either approximation.

For diffusion-limited oxidation cases relevant to the Orion heatshield composed of Avcoat, the FullyCoupled approach was found to predict $\dot{m}_{c}$ values up to $50 \%$ larger than the Uncoupled approach. This large disagreement was found only for turbulent cases, for which Approximations \#1 and \#2 both result in a lower $\dot{m}_{c}$ value. For laminar cases, Approximations \#1 and \#2 were found to have offsetting effects on the predicted $\dot{m}_{c}$. Thus, the Uncoupled and Fully-Coupled results agreed within 10\%, while the PartiallyCoupled value disagreed by as much as $20 \%$.

\section{Colophon}

This document was typeset by $\mathrm{ATT}_{\mathrm{EX}}$ in Computer Modern font with the AIAA package, ${ }^{\mathrm{a}}$ version 3.8 . Also employed were the array, booktabs, color, dcolumn, fancyvrb, hyperref, subfig, threeparttable, varioref, and wrapfig packages.

\section{References}

${ }^{1}$ Thompson, R. A. and Gnoffo, P. A., "Implementation of a Blowing Boundary Condition in the LAURA Code," AIAA Paper 2008-1243, 2008.

${ }^{2}$ Martinelli, S., Ruffin, S., McDaniel, R., Brown, J., Wright, M., and Hash, D., "Validation Process for Blowing and Transpiration Cooling in DPLR," AIAA Paper 2007-4255, 2007.

${ }^{3}$ Lees, L., "Convective Heat Transfer with Mass Addition and Chemical Reactions," Combustion and propulsion third agard colloquium, March 1958.

${ }^{4}$ Bianchi, D., Nasuti, F., Martelli, E., and Onofri, M., "A Numerical Approach for High-Temperature Flows over Ablating Surfaces," AIAA Paper 2007-4537, June 2007.

${ }^{5}$ Mcbride, B. J., Zehe, M. J., and Gordon, S., "NASA Glenn Coefficients for Calculating Coefficients for Calculating Thermodynamic Properties of Individual Species," NASA TP 2002-211556, 2002.

${ }^{6}$ Wright, M. J., Bose, D., Palmer, G., and Levin, E., "Recommended Collision Integrals for Transport Property Computations 1: Air Species," AIAA Journal, Vol. 43, No. 12, 2005, pp. 2558-2564.

${ }^{7}$ Wright, M. J., Hwang, H., and Schwenke, D. W., "Recommended Collision Integrals for Transport Property Computations Part 2: Mars and Venus Entries," AIAA Journal, Vol. 45, No. 1, 2007, pp. 281-288.

${ }^{8}$ Svhehla, R. A., "Estimated Viscosities and Thermal Conductivities of Gases at High Temperatures," NASA TR R 142 , 1962.

${ }^{9}$ Park, C., Jaffe, R. L., and Partridge, H., "Chemical-Kinetic Parameters of Hyperbolic Earth Entry," Journal of Thermophysics and Heat Transfer, Vol. 15, No. 1, 2001, pp. 76-90.

${ }^{10}$ Park, C., "Review of Chemical-Kinetic Problems for Future NASA Missions, I: Earth Entries," Journal of Thermophysics and Heat Transfer, Vol. 7, No. 3, 1993, pp. 385-398.

${ }^{11}$ Gokcen, T., "N $\mathrm{N}_{2}-\mathrm{CH}_{4}$-Ar Chemical Kinetic Model for Simulations of Atmospheric Entry to Titan," AIAA Paper 20042469, July 2004.

${ }^{12}$ Fujita, K., Yamada, T., and Ishii, N., "Impacts of Ablation Gas Kinetics on Hyperbolic Entry Radiative Heating," AIAA Paper 2006-1185, Jan. 2006.

${ }^{13}$ Mick, H. J. and Roth, P., "High-Temperature Kinetics of Si Atom Oxidation by NO Based on Si, N, and O Atom Measurements," Journal of Physical Chemistry, Vol. 97, 1993, pp. 6839-6842.

${ }^{14}$ Mick, H. J. and Roth, P., "Shock Tube Study of Silicon Atom Oxidation by CO and $\mathrm{CO}_{2}$," Journal of Physical Chemistry, Vol. 98, 1994, pp. 7844-7847.

${ }^{15}$ Gnoffo, P. A., Johnston, C. O., and Thompson, R., "Implementation of Radiation, Ablation, and Free Energy Minimization Modules for Coupled Simulations of Hypersonic Flow," AIAA Paper 2009-1399, Jan. 2009.

${ }^{16}$ Sutton, K. and Gnoffo, P. A., "Multi-Component Diffusion with Application to Computational Aerothermodynamics," AIAA Paper $98-2575,1998$.

a aiaa-latex.googlecode.com, last accessed January 12th, 2008. 
${ }^{17}$ Gnoffo, P. A., Weilmuenster, K. J., Hamilton, H. H., Olynick, D. A., and Venkatapathy, E., "Computational Aerothermodynamic Design Issues for Hypersonic Vehicles," Journal of Spacecraft \& Rockets, Vol. 36, No. 1, 1999, pp. 21-43.

${ }^{18}$ Gosse, R. and Candler, G., "Diffusion Model Comparisons for Direct Reentry Applications," AIAA Paper 2003-3635, 2003.

${ }^{19}$ Rini, P. and Degrez, G., "Elemental Demixing in Air and Carbon Dioxide Stagnation-Line Flows," Journal of Thermophysics and Heat Transfer, Vol. 18, No. 4, 2004, pp. 511-518.

${ }^{20}$ Kendall, R. M. and Bartlett, E. P., "Nonsimilar Solution of the Multicomponent Laminar Boundary Layer by an Integral Matrix Method," AIAA Journal, Vol. 6, No. 6, 1968, pp. 1089-1097.

${ }^{21}$ Gupta, R. N., Lee, K. P., Zoby, E. V., Moss, J. N., and Thompson, R. A., "Hypersonic Viscous Shock-Layer Solutions over Long Slender Bodies-Part I: High Reynolds Number Flows," Journal of Spacecraft \& Rockets, Vol. 27, No. 2, 1990, pp. $175-184$.

${ }^{22}$ Cheatwood, F. M. and Thompson, R. A., "The Addition of Algebraic Turbulence Modeling to Program LAURA," NASA TM 107758, 1993.

${ }^{23}$ Cebeci, T., "Variation of the Van Driest Damping Parameter with Mass Transfer," AIAA Journal, Vol. 11, No. 2, 1973, pp. $237-238$

${ }^{24}$ Bushnell, D. and Beckwith, I. E., "Calculation of Nonequilibrium Hypersonic Turbulent Boundary Layers and Comparisons with Experimental Data," AIAA Journal, Vol. 8, No. 8, 1970, pp. 1462-1469.

${ }^{25}$ Bartlett, E. P., Abbett, M. J., Nicolet, W. E., and Moyer, C. B., "Improved Heat-Shield Design Procedures for Manned Entry Systems," NASA CR 108689, 1970.

${ }^{26}$ Olynick, D., Chen, Y.-K., and Tauber, M. E., "Aerothermodynamics of the Stardust Sample Return Capsule," Journal of Spacecraft \&3 Rockets, Vol. 36, No. 3, 1999, pp. 442-462.

${ }^{27}$ Gupta, R. N., "Aerothermodynamic Analysis of Stardust Sample Return Capsule with Coupled Radiation and Ablation," Journal of Spacecraft \& Rockets, Vol. 37, No. 4, 2000, pp. 507-514.

${ }^{28}$ Kendall, R. M., Anderson, L. W., and Augier, R. H., "Nonsimilar Solution for Laminar and Turbulent Boundary-Layer Flows over Ablating Surfaces," AIAA Journal, Vol. 10, No. 9, 1972, pp. 1230-1236.

${ }^{29}$ Bartlett, E. P., Anderson, L. W., and Curry, D. M., "An Evaluation of Ablation Mechanisms for the Apollo Heat Shield Material," Journal of Spacecraft \& Rockets, Vol. 8, No. 5, 1971, pp. 463-469. 